\title{
The Use of Augmentative and Alternative Communication to Support People With Intellectual Disability
}

\author{
Andrei Carniel, ITA, andrei.carniel@gmail.com \\ Carla Diacui Medeiros Berkenbrock, UDESC, carla.berkenbrock@udesc.br
}

\begin{abstract}
Augmentative and Alternative Communication (AAC) is a strategy to deal with communication deficiencies. Such deficiencies are presented in people with Intellectual Disability (ID). AAC exploits more than one communication channel to send messages, however it cannot ensure that communication happens. In this paper we develop a prototype of collaborative system to support the communication of people with ID. We employ Design Science Research (DSR) and Participatory Design (PD) to tackle the problem. PD is used in the three design cycles of DSR, which are: knowledge about the user; adaptation of a communication model; and development of screens prototypes. The results are requirements related to communication of people with ID.
\end{abstract}

Keywords: Augmentative and Alternative Communication (AAC); Intellectual Disability; Design Science Research (DSR); Participatory Design (PD).

\section{Introduction}

The deficiency in communication can compromise the interaction, understanding, learning, as well as sharing of ideas and feelings (JORGENSON; PAPCIAK, 1981). Communication disabilities include failures to develop useful speech as well as express oneself using a language effectively. Problems include speech with repetitions and delays, as well as limited understanding of abstract concepts. People with Intellectual Disability (ID) present communication disabilities, which is associated with Autism Spectrum Disorder and Down syndrome. A person with ID may present another difficulties, such as: cognitive problems, poor verbal memory and learning difficulty (KELLY; GOOCH; WATTS, 2015). But not always the message is clear, and there is no single solution to communicate effectively (SHARMA; PATTERSON, 1999).

Augmentative and Alternative Communication (AAC) encompasses the communication methods used to supplement or replace speech or writing for those with impairments in the production or comprehension of spoken or written language. This form of communication is not restricted to just one communication channel (WHEELER; WOLF; KUBER, 2013). It allows the combination of many types of communication, such as facial expressions, body expressions, the use of gestures, sounds, images, texts, and others (HUIJBREGTS; WALLACE, 2015). Despite that, devices such as notebooks, smartphones, and tablets can work together in this scenario. Mobile devices are considered more intuitive and they are convenient for communication, portable, and include a diversity of applications (STILL et al., 2015). For instance, the smartphones have the ability to engage their users (BLACK et al., 2012). Such devices can also support the communication and interaction for people with intellectual disability (LIU; DING; GU, 2016), given that mobile devices are frequently used by users in social interactions and collaborative tasks (PORCHERON; FISCHER; SHARPLES, 2016). We conjecture that mobile devices together with AAC can have potential to support the communication of people with ID. DOI: 
This paper presents a study of the AAC use with mobile devices to support the communication of people with intellectual disabilities. We also presents the development of an AAC based collaborative system prototype for mobile devices. The remainder of this paper is organized as follows: section 2 presents the related works; section 3 shows the use of DSR methodology, as well as the outcomes obtained; section 4 discusses the work done; and, section 5 presents our findings and concluding remarks.

\section{Related Works}

Rolf Black et al. (BLACK et al., 2012) conduct a study on the effectiveness of generating phrases based on the day to day of each person, in order to support the interaction of people with disabilities in a dialogue. They highlight the use of collaboration. In their work a therapist is responsible for organizing the sentences to assist the communication of people with cerebral palsy. Sentences are organized according to information collected of user daily through sensors and data collections.

Waller, Black, and O'Mara (WALLER et al., 2009) analyze the use of an application to tell histories and jokes in order to facilitate communication and increase interaction opportunities to kids with cerebral palsy. The authors also use a software for communication of people with cerebral palsy, in order to generate more interactive dialogue.

Hong et al. (HONG et al., 2014) conduct a study about accuracy of implantation of AAC to an adult with Autistic Spectrum Disorder (ASD). They analyzed the differences of AAC using two perspectives: initially without use of proposed rules of AAC and after using the proposed rules. They studied people without functional speech as well as they accomplished the study of one person who used printed images for communication.

The present paper uses collaboration to personalize AAC so that professionals and family members can work together. We also study people without functional speech and that use folders with printed images to communicate with others.

\section{Application of DSR Methodology}

In this section, we present the application of DSR. We follow the three cycles of DSR.

\subsection{Problem Relevance}

To initiate the use of DSR it is necessary to have the application domain, and specify the opportunities and the context where the research will be accomplished (HEVNER, 2007). To identify the problem scope, DSR provides a set of guidelines that must be followed (HEVNER et al., 2004).

The person with communication disability, independent of his age, despite his effort and successive attempts may not be able to communicate. The lack of understanding for communication, besides limiting social life, can generate feelings such as anguish and aggressiveness, since any person has the need to communicate. Besides that, communication is essential for social development and education of a person (DESAI et al., 2014).

In this context, this paper aims to support the communication of people with ID through use of mobile devices and collaborative systems, to develop an AAC system according to the user's needs. In this way, it is proposed a system where professionals and responsible persons collaborate to the development of the personalized AAC for the user. The AAC system will be developed to provide a more effective communication form DOI: 
that is close to user reality, facilitating in the elaboration of sentences and expression of communication.

\subsection{Problem of Communication}

In the first stage of design cycle we conducted a field research in a clinic specialized in working with people with ID and problems of communication. The field research consisted of performing interviews with the professionals of the clinic, a patient and his responsible.

The therapist reports that the problem of lack of communication can generate negative feelings, such as anguish, and sometimes the persistence these problem can trigger aggressive acts. Another situation reported is called Dialogue of Coexistence (group members living together). This dialogue is characterized by the occupational therapist as a dialogue usually practiced within the family context, where expressions such as sounds and gestures have meanings. Although this form of communication is easy for the people belonging to the group, the dialogue is not easily understandable to all people, especially outsiders. Often people with ID want to communicate, know what they want, but cannot express themselves.

In this research we work with a patient, who has cerebral palsy, dyspraxia (neurological motor dysfunction that prevents the brain from performing the movements correctly) and elevated psychomotor difficulty. The patient enjoys writing (only by copying text; he cannot express himself in writing). He has a good memory and sense of location, sometimes he has disobedient behaviour (the patient does not accept performing the activities), and he has no functional speech. After beginning the accompaniment with controlled medication the patient had improvement in attention and coordination, and was able to maintain eye contact. Although he has a psychomotor disability, the patient can use smartphone, he knows how to play video games and understands the goals of the game.

To facilitate the communication, parents and therapists created their own picture communication system, that consist in a folder with printed images. The folder is made up of the figures retrieved from the Internet, and organized in categories. The patient takes the folder with him everywhere. The folder was produced with a set of images and adapted throughout the use, where parents and professionals were involved in analyzing the most used images and the images that are understood by the patient. When the patient does not understand the images, it is necessary to replace them with images that are part of his daily life. In this case, the best option reported by the responsible is using photos.

In addition to the communication problem, some of the patients have concentration problems. In these cases, presenting complex information can be a difficult task. In some cases, it is necessary to use controlled medication to improve the patient's concentration.

For the responsible person, the fact of patient cannot communicate is frustrating. This made the responsible provide the AAC folder so that patient have the maximum performance. When the image for the intended communication is not in the AAC folder, the patient asks what he needs to the responsible person. The priority is to increase communication in the school context and at home, since they are the places where the patient spequds the jump, 2020 his time. RENOTE DOI: 


\subsection{Proposed Communication Model}

The proposed communication model is an adaptation of several communication models, sociopsychological and sociocultural concepts of many researchers of communication area. The adaptation differs from the Freixo's proposal (FREIXO, 2006), primarily because it is an interpersonal model of communication, not a mass communication model; it is focused on person with ID; and it considers physical and mental disability as aspect that can influence communication. The mass communication is subordinated to the preference and needs of public, and builds on experimental research to discover the factors that impacts the public (MCQUAIL; JESUS; PONTE, 2003).

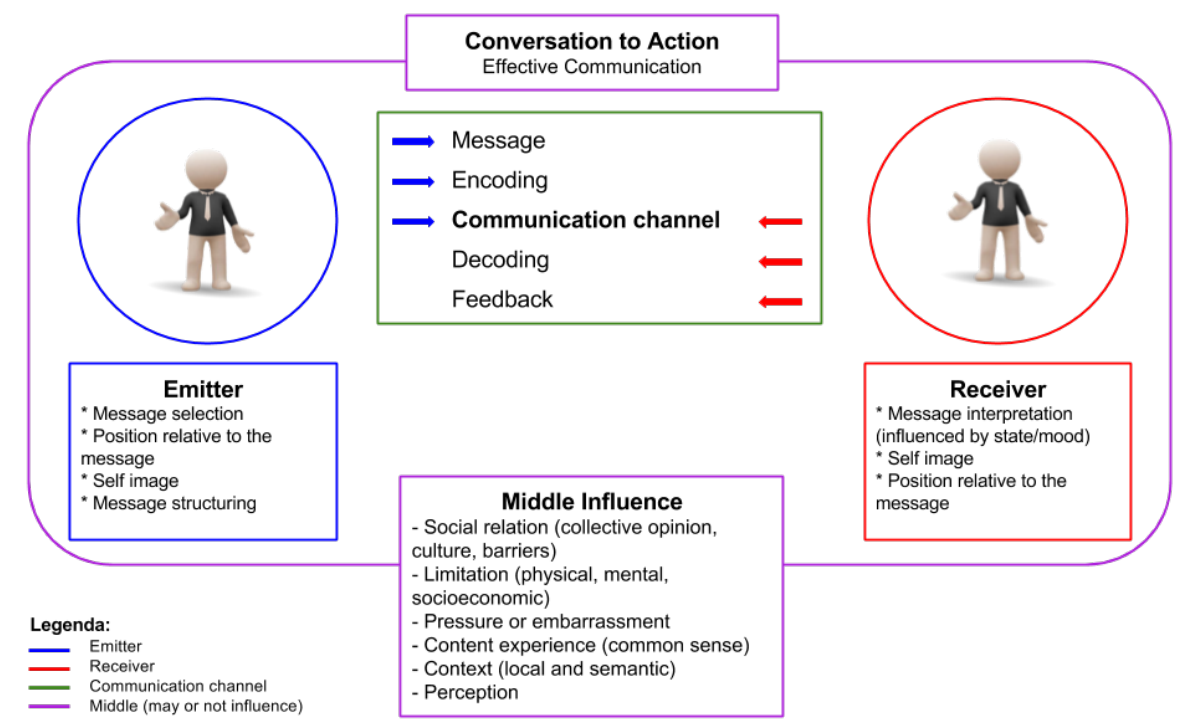

Figure 1. Adapted Communication Model

In the proposed communication model, in Figure 1, the emitter must select the message to be sent. The message contains the emitter position in relation to it, and it must be simple, direct and cohesive; so that it has the same meaning to the receptor. The communication is determined by emitter, according to his position, social status, reputation and experience. The position in relation to the message directly influences its structuring, for example in the choice of figures of languages, expressions and intonations. Efficient communication depends on adapting intercommunication attempts to the occasion, the situation, the subject and the people involved. The message is encoded, transmitted by electronic means, and decoded. This is a concept used in Schramm's Model of Interpersonal Communication, where both emitter and receiver are able to encode and decode the message. This model uses the concept of feedback, in which a reaction occurs according to the message received, contributing to an exchange of influence in the communication between the emitter and receiver. For Schramm, the act of communication is endless, without a specific beginning and a definitive end. This model makes a transition from the linear to the cybernetic model (FREIXO, 2006).

Communication noise is a important feature in this context. The noise is any internal or external element that interferes, hinders or prevents the process of transmission of the message idealized by the sender to the receiver. There are 4 types of noise, they are: physical, physiological, psychological and semantic.

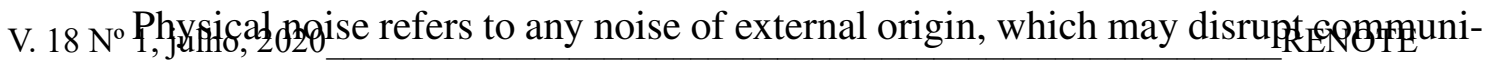
DOI: 
cation. The physiological noise is constituted by factors that hinder the understanding the message by the receiver and prevent it from reasoning right, for example, headache and earache. With psychological noise, the receiver tries to understand the message received, but for some reason he begins to lack attention. It is emphasized that the occurrence of psychological noise is common. They can occur due to tiredness, overwork, worry, among others, but when they become routine they may be related to attention deficit. Semantic noise occurs when the receiver receives a message, but for some reason interprets it differently. This can occur when a message has many technical terms, slang, or even two-way phrases.

When communicating, regardless of the communication channel used, it is necessary to consider the noise during the transmission of a message, so that the idealized sense of the message by the emitter is the same as understood by the receiver, even with the presence of the noise (HAYES; BALL; REDDY, 1981).

Each sent message generates a feedback, a brief reversal of roles where the receiver becomes a emitter for a short period of time, and sends a reaction to the received message. This concept of return of senses began to be used in the 1980s, and was initially introduced in the academic and institutional contexts (JORGENSON; PAPCIAK, 1981). The interlocutors, both the emitter and receiver, have a position in relation to the message. In the case of the emitter, its position will influence when the message is constructed, where the emitter selects the message to be transmitted from his point of view according to his perception.

Perception is the form of an interlocutor to interpret and understand the actions performed (his unique point of view on a given situation). In this way, the positioning in relation to the message will decide how it will be constructed, emphasized and even the type of communication that will be established according to his perception. It is important to highlight that it is necessary to have a shared knowledge, so that both the signals and the meaning of the communication are understood; this knowledge is called common sense (MCCARTHY, 1986).

The receiver will interpret the message and create its position in relation to it. The form of interpretation can be influenced by some factors, for example, the perception of the receiver in relation to the message, the way in which the receiver believes the emitter has positioned, even the receiver's own mood can influence the understanding of the message. These are some factors that may influence the feedback, and the receiver can show his satisfaction with the message, as well as his contributions or new requests (WINOGRAD, 1987). In addition, the reverse process must be considered, when the receiver is not satisfied with the way in which he perceived the message.

In this model the context is seen as a factor that can have high or low influence in the accomplishment of a dialogue, since the context may influence indirectly. For example, in a dialogue between 2 friends where both are inserted in the same way in the same context. The context makes the transmitted message more effective, since the context influences how the message is understood (MCCLELLAND; ELMAN, 1986).

In addition, the context can determine the direction of a communication, since the means is part of the formation of the individuals, as well as their social relations (community opinion, the culture that the interlocutors are inserted and social barriers). The context influences the interpretation and perception of message. In addition, users sharing the same context are more able to interpret messages when compared to users in V. $18 \mathrm{~N}^{\mathrm{o}} 1$, julho, 2020 RENOTE DOI: 
different contexts. The context is also considered an instrument of communication support, reducing ambiguity and increasing expressiveness, acting in advance as an emitter of a known or codified message

Another point that needs be considered is the phrases that can cause pressure or embarrassment according to the culture of a determined society. Physical, mental and socioeconomic limitations may be present with lesser or greater intensity, independent of society. Through the experience of these factors, the individual creates his perception. The mechanisms of perception are some techniques used in a system to provide information and supports the awareness of users (MCCLELLAND; ELMAN, 1986). Context and timing can also influence position, status, reputation and experiences, in a communication.

\subsection{Communication Model and Software}

The third cycle consists of the planning and development of the screens, based on the previous cycles and Participatory Design. This cycle has the purpose of evaluating if the prototypes idealized by the author fit the model needed by the users. In the first stage of prototypes, the screens were idealized looking for its functionality, and the smallest number of components on the screen. In this way, the prototypes were designed in order to have the necessary functions to use AAC

One of the techniques of Participatory Design is to show prototypes to the end user to be evaluated. In this step, the first prototype, shown in Figure 2, was initially evaluated by the professionals. As a positive return, two features were highlighted: the simplicity of the screen; the functionality to reproduce the sound of the communication (through a button).

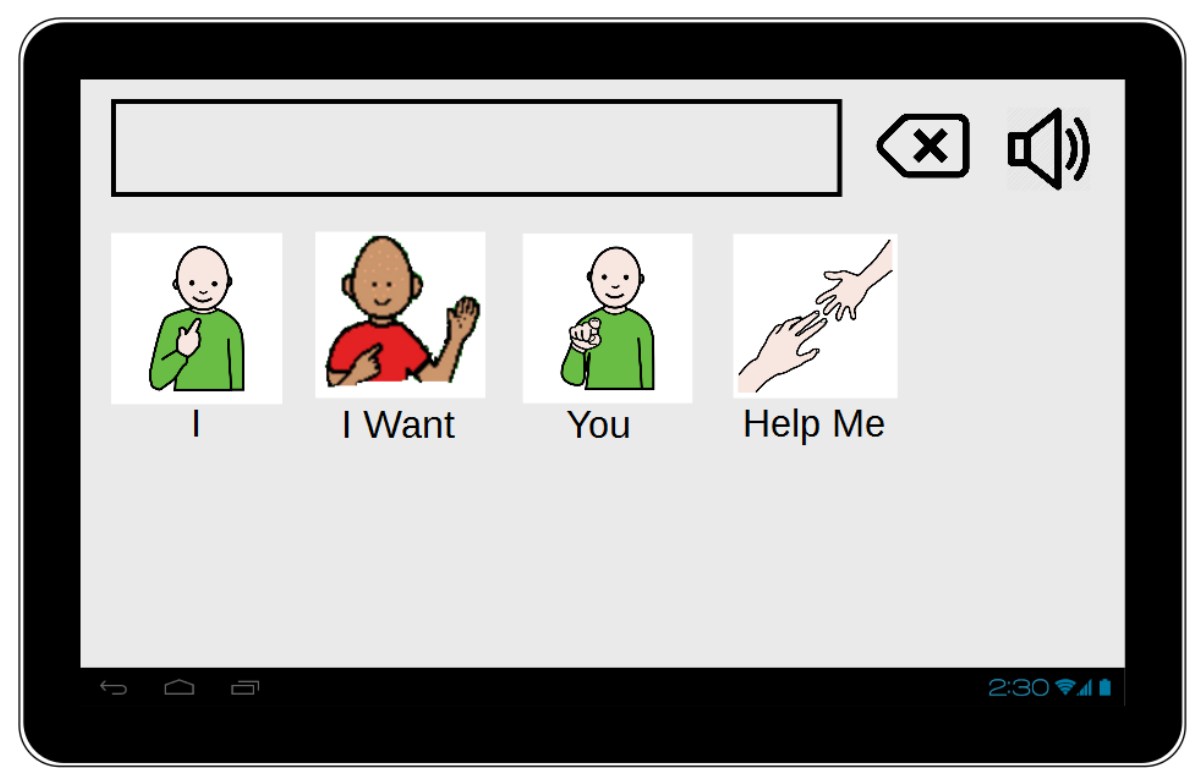

Figure 2. First prototype screen

According to the professionals, sound replay is a very important step to understand and learn communication. Two negative points were highlighted: the first is that the patient rarely uses the "I" option, but rather a "I Want" option; the second point is that the "I" option usually has as a representation for a picture of the person who is using the

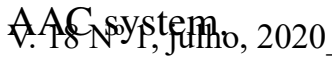
RENOTE DOI: 
The screens were built to be similar in order to reduce learning time; and automated, so that when selecting a subject the software automatically plays the sound and displays the actions available to that subject. Another feature of the system is that clicking image makes the voice synthesizer play the text below the image. The option to listen to the complete phrase assembled is played when the option "sound playback" is selected. Figure 3 shows how the communication model influenced the development of software prototypes.

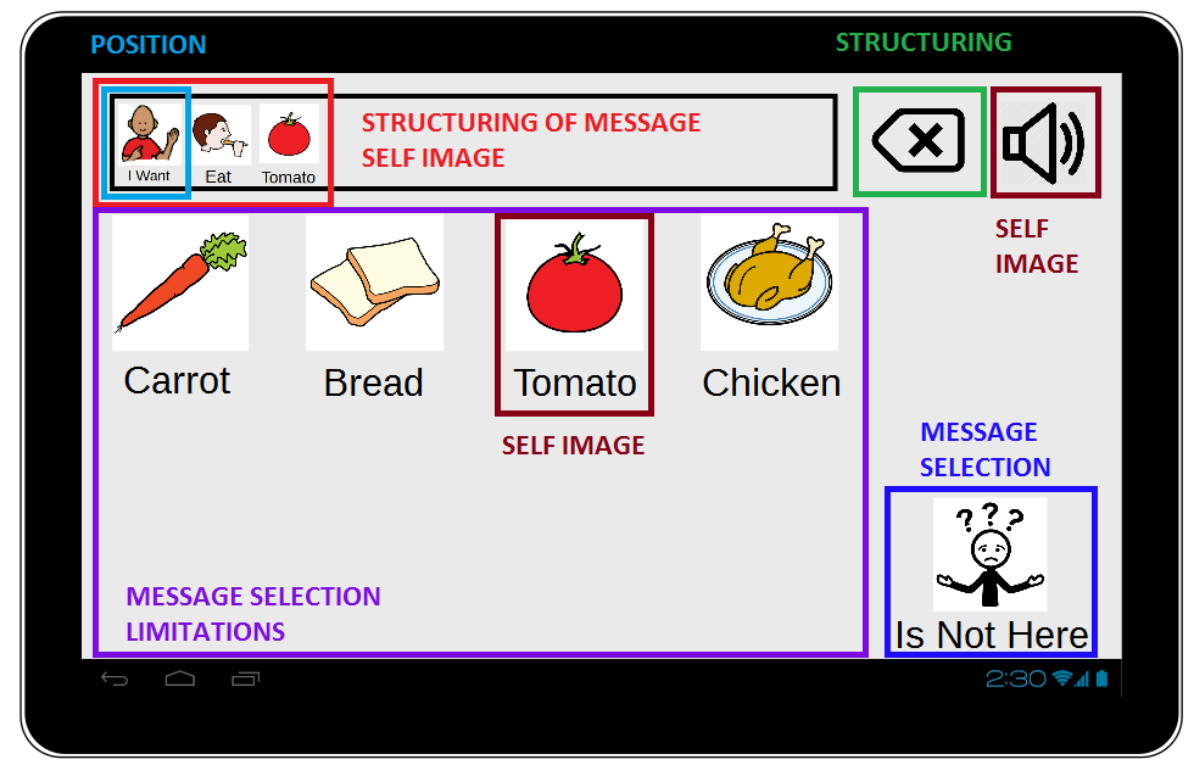

Figure 3. Communication model in prototype

The prototypes were designed only with the elements necessary for communication, and followed the communication model. According to Figure 3, the elements of the communication model can be identified in the software, such as:

- The position of an emitter in relation to the message is represented by the subject (I, you, I want, among others), and if the user wants or needs something;

- The structure of message is represented by the order of presentation of the AAC (subject + action + action option), by the delete button and the selected phrase display box. It is emphasized that the user is not always able to elaborate the desired communication, therefore, organizing the communication in a way that requires less work can facilitate its use;

- The self-image is found in the message design field, the message selection field, and the icon to play the selected message. It needs to be constantly reinforced, since self-image influences how the user interprets the environment, the user himself, and the choice of expressions;

- The message selection is represented by the icons displayed on the screen, and by the "Is Not Here" button, since the system has a finite communication set, and the desired expression may not be available to the user at that time;

- The limitations are mainly related to the size of the images, understanding it, and the ability of the user to use a tablet;

- Finally, social relations, pressure, experience, context and perceptions, become guidelines for the selection of AAC images.

The prototypes were prepared according to the Picture Communication System (PGS)`ppatient folder. Due to the copyright purposes, the similar images werewsed from DOI: 
an online repository (PALAO, 2017), which allows its free use and sharing, except for commercial purposes.

\subsection{Research Rigor}

Before using the software, it is important to know if it adequately supports in the environment that will be used (DIX et al., 2004). In this way, in the relevance cycle it is identified the application domain, as well the problem and opportunities (HEVNER, 2007). This first cycle is used to initiate DSR and supports all other cycles. The first iteration of the design cycle was made in three stages:

1. The first stage is characterized by a field study through meetings and user observation. The aim was to understand the reality of people with disability, together with the needs of these people, and a literature review to search for related works;

2. After the public knowledge, it was necessary to conceptualize how communication occurs, what factors must be considered to establish communication. In general, people have different communication disabilities and different needs (FALCÃO; PRICE, 2012), establishing a single standard or several standards to be used with several people becomes a challenging task. In this way, we consider some elements of mass communication. Mass communication aims to establish communication with all members of a society (MCQUAIL; JESUS; PONTE, 2003), and this fact lead us to use some elements to the development of the prototype;

3 . The third stage is characterized by developing and evaluating the screens prototypes, based on the second iteration of design cycle. The analysis was performed by two professionals, who are used to the patients needs, and have experience to communicate with people with communication disabilities. The evaluation of interface is necessary to evaluate the use quality of a software. The formative assessment seeks to improve the interface, through reviews of negatives and positives points, during the iterative design. The usability test with real users is essential. It provides information about problems of use experience (NIELSEN, 1994).

The rigor cycle presents the scientific ground and engineering methods to provide a foundation of DSR, as well as the knowledge base to this research.

With the professionals participation (occupational therapist and speech therapist) together with the responsible (mother), the communication model was evaluated, as well as the prototypes elaborated. It was also possible to understand some of the needs of the person with Intellectual Disability, and identify some requirements to development of communication model and screens prototypes. The requirements are:

- The need for customization of figures or images, since they can be subjective depending the region where the user is located;

- Explore the meaning of signs using images, text and sounds. Use more than one form of communication and work on restrictions, providing an attractive and easy communication to use;

- Adapt the number and size of screens component's, some people may have sharp vision problems and require larger images and texts;

- Display the interface elements using a consistent and repetitive as possible layout in order to ease memorization and learning ability of the software;

- Facilitate the use of software through logic. For instance, if the user deletes an image, the software must present the previous image category. The rationale is the

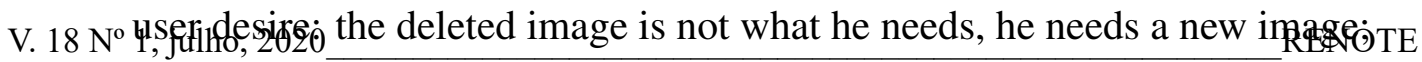
DOI: 
- Separate according to the categories of actions that user have autonomy to perform (category "I" and "I want"), and categories that user needs help (category "You");

- Reinforce the self-image so that person with disability on communication understands the way of communication is accomplished, and can make himself understood by the public.

\section{Discussion}

Based on the evaluation of screens with participatory design it is pointed out that a simple interface can have a better result. The ideal interface must have a reduced number of options available, avoid elements that confuse or distract the user. The experience of use must be customized to persons with ID. The interaction (chaining of screens) must be provided according to the needs of the user.

One of the concepts presented by the professionals of the clinic was the need for a structure of sentences closer to everyday language, following the structure: "subject + action + action option". Communication systems that have a reduced set of signs, or that allows short and quick responses, can make the communication not clear. While this communication structure is adequate to perform communication for quick responses, it may not be the most appropriate form.

The communication is particular for each person, but the structure "subject + action + action option", is common for sentences construction. This structure helps the construction and understanding of a sentence, in addition it is closer of communication practiced everyday.

As for the subject used, it is appropriate to use images that have meanings, as a user photo, pictures of family members, as well as short expressions and regularly used, such as: Yes, No and Help Me. Not all the sentences need a subject, for answering, "yes" and "no" may suffice. One should consider the situation of a person with disability that wants to communicate but does not know how to express.

According to the professionals it is suggested that the choice of action and action option be private to each subject. In other words, subject that indicates first person must be related to actions that user must have autonomy to make. Subject that indicates second or third person must contain actions that user needs some help or another person to make it.

It is also highlighted by professionals, that use of sound has a reinforcement effect for the user to understand pictures and texts. Oral communication is the primary form used by people with ID, but we showed that other forms can help in the communication process.

\section{Conclusion}

This paper aims to identify how the Augmentative and Alternative Communication (AAC) can support people with Intellectual Disability (ID) to communicate, trough the use of mobile device and collaborative systems. To achieve the objectives we used Design Science Research (DSR) and Participatory Design (PD). PD was used in all design cycles of DSR.

DSR aided the research development in incremental form, and PD provided a vision and understanding of the problem from the user's point of view. The two techniques

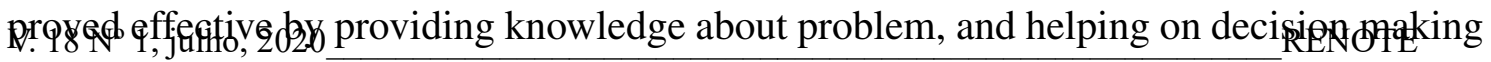
DOI: 
in the development process. The techniques aided the identification of user's needs, adaptation of the communication model, and tests of the prototypes of screens. As a result, we identified the needs and requirements to employ AAC with mobile devices to support the communication of people with ID.

It is also possible to verify that communication is particular to each person. Each individual adopts his/her language expression in order to build an identity and express himself. The next steps are develop the software based on the developed prototype, as well as evaluate its use.

\section{References}

BLACK, R. et al. Supporting personal narrative for children with complex communication needs. ACM Trans. Comput.-Hum. Interact., ACM, New York, NY, USA, v. 19, p. 15:1-15:35, 2012.

DESAI, T. et al. Implementing an ipad-based alternative communication device for a student with cerebral palsy and autism in the classroom via an access technology delivery protocol. Computers \& Education, Elsevier, v. 79, p. 148-158, 2014.

DIX, A. et al. Human-computer Interaction. England: Pearson/Prentice-Hall, 2004.

FALCÃO, T. P.; PRICE, S. Tangibles for students with intellectual disabilities. Proceedings of the 11th International Conference on Interaction Design and Children, ACM, GER, p. 371-374, 2012.

FREIXO, M. J. V. Teorias e modelos de comunicação. Lisboa: Instituto Piaget, 2006.

HAYES, P.; BALL, E.; REDDY, R. Breaking the man-machine communication barrier. Computer, IEEE, v. 14, n. 3, p. 19-30, 1981.

HEVNER, A. R. A Three Cycle View of Design Science Research. Scandinavian Journal of Information Systems, v. 19, n. 2, p. 87-92, 2007.

HEVNER, A. R. et al. Design science in information systems research. MIS quarterly, Springer, v. 28, n. 1, p. 75-105, 2004.

HONG, E. R. et al. Teaching caregivers to implement an augmentative and alternative communication intervention to an adult with asd. Research in Autism Spectrum Disorders, Elsevier, v. 8, n. 5, p. 570-580, 2014.

HUIJBREGTS, T.; WALLACE, J. R. Talkingtiles: Supporting personalization and customization in an aac app for individuals with aphasia. Proceedings of the 2015 International Conference on Interactive Tabletops \& Surfaces, ACM, PRT, p. 63-72, 2015.

JORGENSON, D. O.; PAPCIAK, A. S. The effects of communication, resource feedback, and identifiability on behavior in a simulated commons. Journal of Experimental Social Psychology, Elsevier, v. 17, n. 4, p. 373-385, 1981.

KELLY, R.; GOOCH, D.; WATTS, L. Is' additional'effort always negative?: Understanding discretionary work in interpersonal communications. In: ACM. Proceedings of the 18th ACM Conference Companion on Computer Supported Cooperative Work \& Social Computing. CAN, 2015. p. 191-194.

LIU, P.; DING, X.; GU, N. "helping others makes me happy": Social interaction

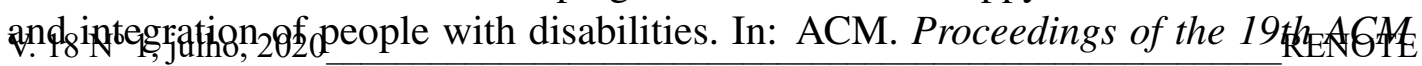
DOI: 
Conference on Computer-Supported Cooperative Work \& Social Computing. USA, 2016. p. 1596-1608.

MCCARTHY, J. Applications of circumscription to formalizing common-sense knowledge. Artificial Intelligence, Elsevier, v. 28, n. 1, p. 89-116, 1986.

MCCLELLAND, J. L.; ELMAN, J. L. The trace model of speech perception. Cognitive psychology, Elsevier, v. 18, n. 1, p. 1-86, 1986.

MCQUAIL, D.; JESUS, C. de; PONTE, C. Teoria da comunicação de massas. Lisboa: Fundação Calouste Gulbenkian, 2003.

NIELSEN, J. Usability engineering. USA: Elsevier, 1994.

PALAO, S. ARASAAC - Aragonese Portal of Augmentative and Alternative Communication. 2017. <http://www.arasaac.org>.

PORCHERON, M.; FISCHER, J. E.; SHARPLES, S. Using mobile phones in pub talk. In: ACM. Proceedings of the 19th ACM Conference on Computer-Supported Cooperative Work \& Social Computing. USA, 2016. p. 1649-1661.

SHARMA, N.; PATTERSON, P. G. The impact of communication effectiveness and service quality on relationship commitment in consumer, professional services. Journal of services marketing, MCB UP Ltd, v. 13, n. 2, p. 151-170, 1999.

STILL, K. et al. Facilitating derived requesting skills with a touchscreen tablet computer for children with autism spectrum disorder. Research in Autism Spectrum Disorders, v. 19, p. 44-58, 2015.

WALLER, A. et al. Evaluating the standup pun generating software with children with cerebral palsy. ACM Trans. Access. Comput., ACM, New York, NY, USA, v. 1, n. 3, p. 16:1-16:27, fev. 2009.

WHEELER, M.; WOLF, F.; KUBER, R. Supporting augmented and alternative communication using a low-cost gestural device. Proceedings of the 15th International ACM SIGACCESS Conference on Computers and Accessibility, ACM, p. 67, 2013.

WINOGRAD, T. A language/action perspective on the design of cooperative work. Human-Computer Interaction, Taylor \& Francis, v. 3, n. 1, p. 3-30, 1987. 